\title{
The Forgotten Mathematician
}

\section{Dattatreya Mukherjee}

\author{
MBBS Student, Jinan University, P.R China
}

\begin{abstract}
:
There are thousands of researchers who are still unrecognized but they had done really ground breaking works. But, due to many reasons they are in the black side of the fame. Many people do not even know their name, so it's very much unusual to expect the knowledge of their works. Dr. Vashishtha Narayan Singh is one of them. He is famous for all his ground breaking works in mathematics, but true how many people from India even know his name. Even Government of India did not recognize this person in his life time. But finally, in 2020, he was awarded Padmashri, the fourth highest civilian award from Government of India. So, there is a big question why India and the world keep this great person unrecognized. In this paper we will try to know this forgotten mathematician and also will try to know why the world never give a proper recognition to this legend.
\end{abstract}

\section{Introduction:}

Dr. Vashishtha Narayan Singh is the example of a true brilliant. He was born in $2^{\text {nd }}$ April 1946 in a police family where his father Lal Bahadur Singh was a police constable at Basantpur village, Bhojpur district, Bihar, India and his mother was Lahaso Devi. (1) His incredible journey from a small village in Bihar's Siwan district to a PhD program at the University of California, Berkeley, in the United States, has all the makings of a great obscurity-to-fame story. He showed early on that he could work with numbers, and a mathematical fairy tale started to unfold. He migrated to Patna Science College in 1963 after finishing school at Netarhat Vidyalaya in present-day Jharkhand, where he had an incredible run. According to Singh's classmates and teachers, the college principal was so pleased that he demanded that the governor and chancellor of the university bend the rules to allow Singh to take the BSc exam in his first year of college and then the MSc exam the following year. Young Singh acquitted himself admirably in both exams and became a phenomenon. (2) In a conference in India, John L Kelly met with Vashishtha and got impressed and he invited Vishishtha to University of California for further research works. "Reproducing Kernels and Operators with Cyclic Vector I", his genius 1969 $\mathrm{PhD}$ dissertation, is widely cited and praised in the field of mathematics. (2) In USA he had worked with NASA and later Vashishtha Narayan Singh had taught at Kanpur's Indian Institute of Technology and Kolkata's Indian Statistical Institute. He was also a visiting lecturer at Madhepura's BN Mandal University.(3) He had also worked at Tata institute of fundamental Researches.

He married a woman who was a daughter of an army person. But it was an unsuccessful marriage and it ends into divorce.

Most Famous Mathematical Work:

His most famous and highly citable work is "Reproducing kernels and operators with a cyclic vector. I" which was published in Pacific Journal of Mathematics in the year 1974, Vol 52, No 2. 


\begin{abstract}
of the paper:
"In this paper a study is begun of the complete unitary invariant $((1-\mathrm{wT}) \sim 1$ e1 $(1-\mathrm{zT}) \sim 1 \mathrm{e})$, first considered by Livsic in his paper 'On Spectral Resolution of Linear Nonself Adjoint Operators' Mat. Sb., 34 (76), 1954, 145-199, of a triple (T, H, e) where T is a bounded linear operator on a Hubert space $\mathrm{H}$ and $\mathrm{e}$ is a cyclic vector for $\mathrm{T}$ in $\mathrm{H}$, as a reproducing kernel. One of the important points is the construction of a subset of the group algebra of the torus closed under pointwise addition and convolution. This obviously will generate a ring called the K-ring. A study of this ring will be done later. Several other theorems and constructions are also given.” (4)

\section{The Story of NASA:}

In an article from The Indian Express (5), Singh's brother talks about this event and he says "He is the 'NASA scientist' who fixed a glitch in the space agency's computers that had backed up 'moments before the launch of the Apollo human spaceflight mission". The computers had malfunctioned for 30-35 seconds and Singh began manually calculating during the time they fixed it. The results produced by Singh and the computers were the same. However, there are no official sources that confirm this story. The results produced by Singh and the computers were the same. However, there are no official sources that confirm this story.
\end{abstract}

\title{
Why this Gifted mind gets unrecognized towards the major part of the world?
}

Most of the mathematician likes to live alone, and Dr Vashishtha was also not excluding them. Once in an interview of Cedric Villani, he said that peace and silence is the key part of mathematical thinking. So, most of the mathematician works at night. But Why Vashishtha Narayan did not get the recognition its due to his disease, that is Schizophrenia. If you know the famous mathematician Dr. Jhon Nash, he had also the same disease but he got Nobel Prize and Abel Prize. But Why not Dr Vashishtha Narayan Singh?

Lets, discuss what is Schizophrenia, It's a mental disease where Dopamine level gets high, just the opposite of the Parkinson. It shows two symptoms, positive symptoms and negative symptoms. It has a genetics role and its curable with proper antipsychotic drugs.

So, lets come to the mail point, if you have seen the movie "The Beautiful Mind" you will realize that how spouse or the family play a key role in this disease. Dr Nash was lucky he got that care from his wife. Bad luck ran for Dr Singh. Failed Marriage and other family problem drained him out totally.

Then, major effect society has played in the two cases. Dr Nash was in America and he got a good support from the society. In India, people do not like Psychiatric patients. They are neglected and many times thrown out of family. There are many superstitions related to these diseases. In 70s scenario was worst and this is also a major cause why most of us do not know Dr Singh.

According to Wikipedia Article (1), after getting diagnosed with schizophrenia, in the late 1970s, as his health deteriorated, he was admitted to the Central Institute of Psychiatry in Kanke (now in Jharkhand), where he lived until 1985. Singh returned to his hometown of Basantpur in 1987. He 
vanished on his way to Pune by train in 1989 and was discovered four years later in Doriganj, Saran district, near Chhapra. After that, he was admitted to Bangalore's National Institute of Mental Health and Neurosciences (NIMHANS). He received treatment at Delhi's Institute of Human Behavior and Allied Sciences (IHBAS) in 2002.

On $14^{\text {th }}$ November 2019, after a prolonged illness, he left us leaving all his great works in mathematics.

\section{Conclusion:}

There are many researches like Dr. Singh, who had done lots of works but due to several reasons they are unrecognized. A researcher never dies, he lives with his research works.

\section{References:}

1. Wikipedia Article About Vashishtha Narayan Singh

2. Article in Economic Times, https://economictimes.indiatimes.com/news/politics-andnation/indias-unknown-beautiful-mind/articleshow/72080015.cms

3. Article of India Today https://www.indiatoday.in/india/story/renowned-mathematician-vashishtha-dies-in-patnafamily-made-to-wait-for-ambulance-1618915-2019-11-14

4. Reproducing kernels and operators with a cyclic vector. I, Pacific Journal of Mathematics, Vol 52, No:2 Feb 1974, 567-584

5. Article of Indian Express, https://indianexpress.com/article/india/vashishthas-worldvashishtha-narayan-singh-mathematician-6144681/ 